\title{
Synthesis of Crystalline Ag Nanoparticles (AgNPs) from Microorganisms
}

\author{
Seema Sharma ${ }^{1}$, Naheed Ahmad ${ }^{2}$, Anuradha Prakash ${ }^{3}$, Vidya Nand Singh ${ }^{4}$, Ashok Kumar Ghosh ${ }^{3}$, \\ Bodh Raj Mehta ${ }^{4}$
}

${ }^{1}$ Department of Physics, A.N College, Patna, India; ${ }^{2}$ University Department of Botany, Patna University, Patna, India; ${ }^{3}$ Department of Water Management, A.N College, Patna, India; ${ }^{4}$ Thin Film Laboratory, Department of Physics, Indian Institute of Technology, New Delhi, India.

Email: seema_sharma26@yahoo.com

Received January $26^{\text {th }}, 2010$; revised February $5^{\text {th }}, 2010$; accepted February $9^{\text {th }}, 2010$.

\begin{abstract}
Bacteria obtained from the isolates of the biodiversity of riverine coast of Ganga identified as Bacillus Koriensis, when challenged with silver nitrate solution accumulated silver nanoparticles on the surface of its cell wall. These nanoparticles showed an absorption peak at $438 \mathrm{~nm}$ in UV-visible spectrum corresponding to the plasmon resonance of AgNPs. The transmission electron micrographs of nanoparticles in aqueous solution showed the production of reasonably monodisperse AgNPs (average particle size: $9.92 \pm 1.311 \mathrm{~nm}$ ) by the bacteria. X-ray diffraction spectrum of the nanoparticles confirmed the formation of metallic silver.
\end{abstract}

Keywords: Crystal Structure, Nanostructures, Metal, AgNPs

\section{Introduction}

Nanostructured materials are being viewed as the future material and for various diverse applications in areas such as biomedical science, optics, mechanics, magnetics catalysts, biosensors and energy science [1-3]. However most synthesis techniques employed involve huge inputs in terms of capital and energy. In the era of growing awareness about increasing pollution and global warming, developing new methods of synthesis of nanomaterials with green technologies is a challenge. Biodiversity is the best resource for biotechnological innovations as organic materials of nanometer dimensions form the basis of life. This diversity of life especially microorganisms is being used as ecofriendly nanofactories for bioproduction and synthesis of different compounds of nanometer size [4-6]. The concept of exploiting locally available species with potential to synthesize extracellular nanoparticles is a novel concept for bioprospecting. It provides valuable leads for new product development and new applications of biological species that have not been studied earlier.

The metal microbe interaction has made the material scientist aware of the immense potential of the microorganisms as ecofriendly nanofactories [6-8]. Biological synthesis of such nanomaterials has gained significant interest due to the use of mild experimental conditions of temperature, $\mathrm{p}_{\mathrm{H}}$ and pressure. If harnessed to their full potential, biological synthesis could present extra advantages over chemical methods such as higher productivity and lower cost. One new dimension in the metal-microbial interaction has emerged in the last few years, is that the synthesis of metallic nanoparticles have been reported from bacteria, yeast, fungi, and other biological sources [9-16].

Bacteria are ubiquitous and constantly exposed to stressful situations; hence they develop diverse ways to resist and survive. When exposed to metals or other toxic substances beyond a certain level they develop many mechanisms such as efflux, alteration in the solubility and toxicity by change in redox state of the metalion, extracellular complexation or precipitation of metals and the lack of specific metal transport systems [17-19]. The exact mechanism leading to the formation of reduction to silver ions and formation of nanoparticles is not fully understood. However, it is known that the tolerance of bacterial cells and formation of mineral particles is very much dependant on the composition of the growth environment.

Various workers have exploited various microorganisms for nanosynthesis. Bacteria as for instance Bacillus subtilis 168 was reported to reduce $\mathrm{Au}^{+}$to nanoscale dimensions [20,21].Other bacterial strains like Pseudomonas stutzeri $\mathrm{Ag} 259$ were found to be silver resistant and were able to produce nanosize silver [22].Other workers have used the fungi like Fusarium oxysporum and Veri- 
cillium to produce Magnetite, Silica and Titania [23-25]. Klebsiella aerogens was manipulated to produce $\mathrm{Cds}$ nanoparticles extracellularly. In addition to gold and silver nanoparticles synthesis of semiconductors like $\mathrm{CdS}$, $\mathrm{ZnS}$ and $\mathrm{PbS}$ have been obtained from bioorganisms. Clostridium thermoaceticum precipitates was observed to precipitate $\mathrm{CdS}$ at the cell surface as well as the medium from $\mathrm{CdCl}_{2}$ in presence of cystenine hydrochloride in the growth media [26]. It was also reported that the monodispersity of silver/gold nanoparticles produced either intra or extracellularly by these bioorganisms is not very high or inferior to those obtained by the conventional chemical methods [27].

$\mathrm{Ag}$ Nanoparticles (AgNPs) have received considerable attention due to their attractive physicochemical properties.The surface plasmon resonance and large effective scattering cross section of individual AgNPs make them ideal candidates for molecular labelling [28]. The existing physical methods for AgNPs synthesis, such as gas condensation and irradiation by ultraviolet or gradiation, are usually associated with a low production rate and high expense. Further, the largescale synthesis of silver nanomaterial suffers from issues such as polydispersity and stability, especially if the reduction is carried out in aqueous media. Therefore the extracellular biological synthesis of AgNPs could be an attractive and ecologically friendly alternative method for the preparation of large quantities because it offers the advantage of easy downstream processing. Moreover, bacteria are easy to handle and can be manipulated genetically without much difficulty. Considering these advantages, a bacterial system could prove to be an excellent alternative for the extracellular synthesis of AgNPs. Ionic silver is highly toxic to most bacterial cells and has long been used as a potent bactericidal agent [29]. However, several silver-resistant bacterial strains have been reported and even shown to accumulate AgNPs in their periplasmic space $[4,14,15]$.

In this paper, we explore the local biodiversity for commercially valuable biological and genetic resources, as they offer great opportunity for searching more environment friendly biomolecules as an answer to cleaner technologies for sustainable development. Biosynthesis of nanomaterials is carried out from the microbial diversity obtained from the state of India, Bihar (rich fertile alluvial Gangetic plain). Bacillus species has been used to synthesize silver nanoparticles which was isolated from the Gangetic riverine belt was seen to synthesize silver nanoparticles extracellularly. This is the first report when the microbial diversity of the Gangetic plain has been tapped for nanosynthesis. The extracellular synthesis offers a great advantage over an intracellular process of synthesis from the application point of view. Since the nanoparticles formed inside the biomass would have required additional step of processing for release of the nanoparticles from the biomass by ultrasound treatment or by reaction with suitable detergents. The extracellular synthesis of nanoparticle makes it possible to harness and immobilize/deposit onto desired solid support for the use of different practical purposes.

\section{Experimental Details}

\subsection{Culture}

Soil samples were collected from the banks of Ganges at various places in Patna, capital of Bihar during an exhaustive screening programme undertaken in our laboratory to isolate microorganisms capable of synthesizing metal-based nanoparticles. The intracellular silver accumulation was negligible $(<1 \%)$. However, extracellular precipitation of black silver was observed with no loss in the viability of cells. The bacteria selected for this study was gram positive and rod shaped, forming chain like colonies and was identified as Bacillus koriensis (Figure 1). The selection was based on the criteria that this bacterium was tolerating and reducing heavy metals.

\subsection{Production of Silver Nanoparticles}

Serial dilutions were made and plated on nutrient agar plates for culture of the bacteria. The plates were incubated, after the requisite period the colonies were picked up and pure cultures were isolated. The cultures were then checked for their silver resistant properties by spot inoculation with increasing concentrations of $\mathrm{AgNO}_{3}$. The selected culture Bacillus Koriensis sp. was then inoculated in at $0.5 \%$ level in 21 Erlenmeyer flasks containing MGYP (Malt extract $1 \%$, glucose $1 \%$, yeast extract $0.3 \%$, Peptone $0.5 \%$ ) media and incubated at room temperature till the absorbance of the culture was between 0.8-0.9 and the media was observed to be turbid. Colour changes were observed both before and after exposure to sunlight. Silver in form of $\mathrm{AgNO}_{3}$ from $1 \mathrm{mM}$ to $8 \mathrm{mM}$ was then

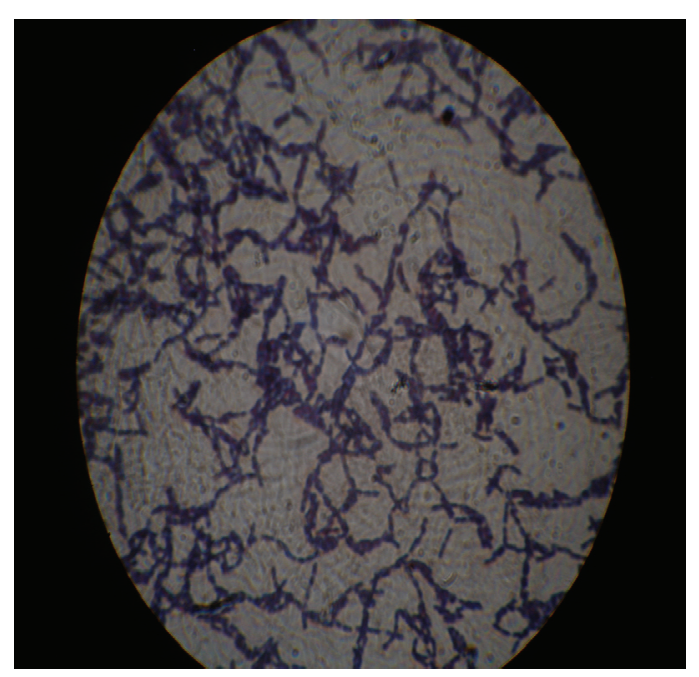

Figure 1. Photograph of Bacillus koriensis sp 
added and left for further incubation. The culture supernatant that was obtained at different time intervals after the addition of aqueous $\mathrm{AgNO}_{3}$ solution was centrifuged at $3000 \mathrm{rpm}$ for $5 \mathrm{~min}$ prior to harvesting bacterial cells; the supernatant was filtered through a $0.22-\mathrm{mm}$ filter, and centrifuged again at $8000 \mathrm{rpm}$ for $15 \mathrm{~min}$ to precipitate AgNPs. While the Bacillus Koriensis sp. incubated with deionized water (positive control) retained its original colour, the silver nitrate treated organism turned dark red after $24 \mathrm{~h}$ due to the deposition of silver nanoparticles. This colour is primarily due to the surface plasmon resonance of deposited silver nanoparticles. In case of negative control (silver nitrate solution alone), no change in colour was observed even after 10 days.

\subsection{Characterization of AgNPs}

\subsubsection{UV-Visible Spectral Analysis}

The optical absorbance of silver nano particles suspended in distilled water was recorded on UV VIS spectrophotometer (Systronics 2202 double beam model) from wavelengths 200-800 nm. The formation and quality of compounds were checked by XRD technique.

\subsubsection{X-Ray Diffraction Analysis}

The X-ray diffraction (XRD) pattern measurements of drop-coated films AgNPs on glass substrate were recorded in a wide range of Bragg angles $2 \theta$ at a scanning rate of $2^{0} \mathrm{~min}^{-1}$, carried out on a Philips PW 1830 instrument that was operated at a voltage of $40 \mathrm{kV}$ and a current of

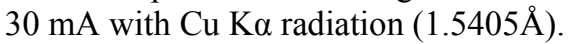

\subsubsection{TEM and Electron Diffraction Analysis}

High Resolution Transmission Electron Microscopy (HRTEM) was performed by TECHNAI G20-STWIN (200 KV) machine with a line resolution 2.32 (in angstrom). These images were taken by drop coating AgNPs on a carboncoated copper grid. Energy Dispersive Absorption Spectroscopy photograph of AgNPs were carried out by the HRTEM equipment as mentioned above.

\section{Results and Discussions}

Figure 2(a) shows the characteristic Surface Plasmon Resonance (SPR) peak for AgNPs [30] obtained from Baccilus koriensis, which was absent in all appropriate simultaneously run controls. The AgNP production was not detected even in a closely related genus of the same family of E. coli, which indicates that the phenomenon could be specific to silver-resistant Baccilus koriensis. Production optimization of AgNPs was performed with respect to concentrations of $\mathrm{Ag}^{+}$ions, which ranged from 1 to $8 \mathrm{mM}$. It clearly showed an increase in the intensity of the SPR up to $4 \mathrm{mM}$ concentration, and an intensity decrease at higher concentrations. The results clearly indicated that $44 \mathrm{mM}$ concentration of $\mathrm{Ag}^{+}$ions was most appropriate for the synthesis of AgNPs from Baccilus koriensis. While no absorption band was observed

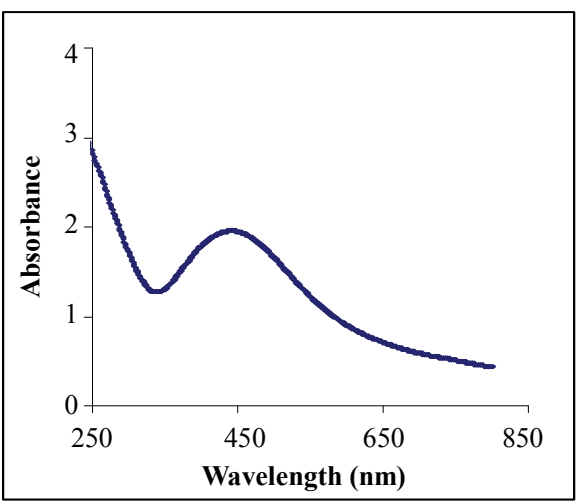

(a)

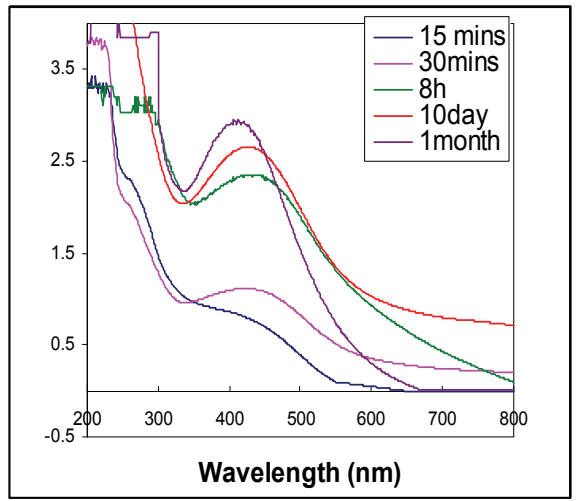

(b)

Figure 2. UV/Vis spectra recorded from the culture supernatant that shows the production of AgNPs (a) after $24 \mathrm{~h}$ of reaction; (b) stability on storage of AgNPs

in both controls (positive and negative), a characteristic surface Plasmon absorption band at $438 \mathrm{~nm}$ was observed at $6 \mathrm{~h}$ that attained the maximum intensity after 24 h. After $24 \mathrm{~h}$ of incubation, no change in intensity at 438 $\mathrm{nm}$ was observed indicating complete reduction of silver ions. The Plasmon bands are broad with an absorption tail in the longer wavelengths, which could be in principle due to the size distribution of the particles [31]. Since the varying intensity of the plasmon resonance depends on the cluster size, the number of particles cannot be related linearly to the absorbance intensities [31].

Nanoparticles find various applications in electronics, optoelectronics etc. in some of these applications it is a requirement that the particles are stable in certain organic solvents. Hence, the stability of the culture in organic solvents such as ethanol, acetone and diethyl ether was determined. It was observed that the Ag solution was soluble in ethanol and no shift in absorbance maxima was observed when the absorbance measurements of the silver nanoparticles suspended in ethanol were taken. However, the particles did not disperse uniformly in acetone and diethyl ether and precipitated. The stability of the synthesized silver nanoparticles was studied by 
measuring its intensity over a period of 1 month in room temperature. A narrow peak at $\sim 280 \mathrm{~nm}$ can be attributed to the presence of contaminating proteins in the sample. No significant change in the intensity was observed which proved its stability over a period of 1 month indicating that the coating polymer is not allowing the agglomeration of the particles (Figure 2(b)). This may be described by the fact that bacterial cells to protect itself from the toxic environment of the silver takes advantage of the detoxification mechanism by precipitation of silver to elemental silver, following the interaction of metal with chemical reactive group located at the bacterial surface or its translocation into the cell. These sites nulcleate deposition of metal chemical precipitate, thus leading to formation of more metals as chemical precipitate and lead to the formation of mineralized crystalline particles. Such a response results in detoxification of $\mathrm{Ag}^{+}$because $\mathrm{AgO}$ is less toxic. The silver cation $\left(\mathrm{Ag}^{+}\right)$is a highly reactive chemical structure which binds strongly to electron donor groups containing sulfur, oxygen, or nitrogen and these bindings with biomolecules like protein could restrict the size of the particle [32]. Whatever the mechanism, the production of silver based crystalline particles seems to be connected with the ability of bacterial cell to survive in an environment that would be highly toxic to other bacteria.

The bacteria were found to be reducing the silver extracellularly. The biosynthesis and reduction of metal was indicated by change in colour. The colour changed from golden yellow which turned to tea brown on addition of $\mathrm{AgNO}_{3}$ after 24 hours (Figure 3). There was perceptible reduction in time of biosynthesis when the bacteria in log phase with $\mathrm{AgNO}_{3}$ was exposed to sunlight.

$\mathrm{X}$-ray diffraction (XRD) pattern (Figure 4) shows intense Bragg's reflections that can be indexed on the basis of the fcc structure of silver [33]. The XRD pattern thus obtained clearly shows [111], [200], [220], and [311] planes, and exhibit that the synthesized AgNPs by the Bacillus koriensis were crystalline in nature. The diffraction peaks were found to be broad around their bases indicating that the silver particles are in nanosizes. The peak broadening at half maximum intensity of the X-ray diffraction lines is due to a reduction in crystallite size, flattening and micro-strains within the diffracting domains.

Scherrer's equation for broadening resulting from a small crystalline size, the mean, effective or apparent dimension of the crystalline composing the powder is

$$
\mathrm{P}_{\mathrm{hkl}}=\mathrm{k} \lambda / \beta_{1 / 2} \cos \theta
$$

where $\theta$ and $\lambda$ have their usual meaning, $\beta$ is the breadth of the pure diffraction profile in radians on $2 \theta$ scale and $\mathrm{k}$ is a constant approximately equal to unity and related both to the crystalline shape and to the way in which $\beta$ is defined. The best possible value of $\mathrm{k}$ has been estimated as 0.89 . The particle sizes of all the samples in our study

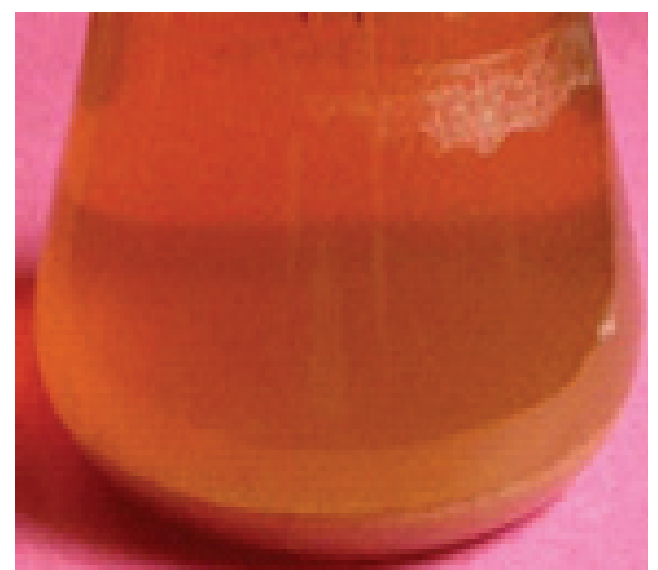

(a)

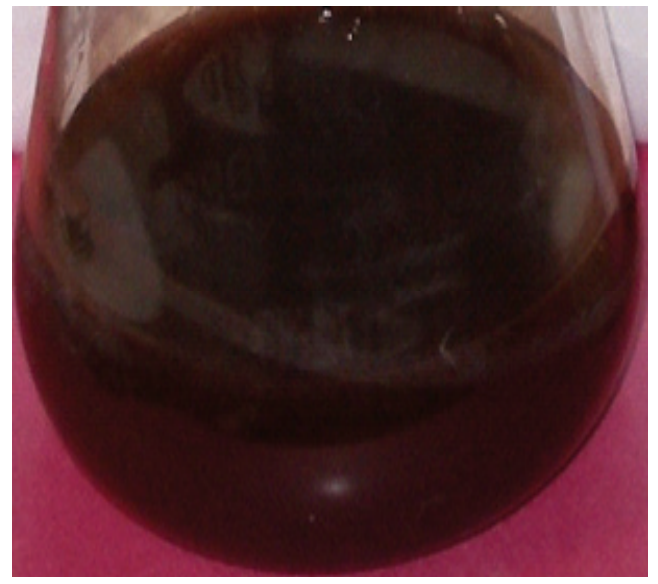

(b)

Figure 3. Photographs showing change in colour after adding $\mathrm{AgNO}_{3 .}$ (a) after 6hrs; (b) after 24hrs

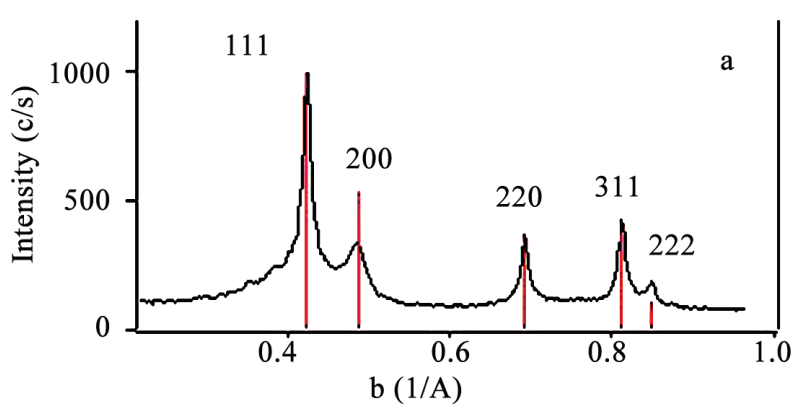

Figure 4. X-ray diffractogram of silver nanoparticles: (a) angular and background corrected raw data with structure factors of Ag represented by vertical bars

have been estimated by using the above Scherrer's equation and was found to be $\sim 10 \mathrm{~nm}$ for the strongest peak.

Transmission electron microscopy (TEM) images of AgNPs that were synthesized by Bacillus koriensis, indicated that the nanoparticles were in the size range of $\sim 10$ 
nm (Figures 5(a) and (b)). Selected area electron diffraction (SAED) spots that corresponded to the (from inside to outside of the central ring) [111], [200], [220], [311] and [222] planes of the face-centered cubic (fcc) structure of elemental silver [21] are clearly seen in Figure 5(c). HRT-EM image (Figure 5(d)) shows the d spacing of 2.02 $\AA$, which matches with the [200] plane of AgNPs.

Figure 6 shows the Energy Dispersive Absorption Spectroscopy photograph of AgNPs. All the peaks of Ag are observed and are assigned. Peaks for $\mathrm{Cu}$ and $\mathrm{C}$ are from the grid used and the peaks for $\mathrm{S}, \mathrm{P}$ and $\mathrm{N}$ correspond to the protein capping over the AgNPs. It is reported earlier that proteins can bind to nanoparticles either through free amine groups or cysteine residues in the proteins [34, 35 ] and via the electrostatic attraction of negatively charged carboxylate groups in enzymes present in the cell wall of mycelia [36] and therefore, stabilization of the silver nanoparticles by protein is a possibility. The amide linkages between amino acid residues in proteins give rise to the well-known signatures in the infrared region of the electromagnetic spectrum and have been shown by the FTIR spectrum [37]. In future, it would be important to understand the biochemical and molecular mechanism of the synthesis of the nanoparticles by the cell filtrate in order to achieve better control over size and polydispersity of the nanoparticles.

\section{Conclusions}

Biosorption mechanism of metal ions by microorganisms includes ion exchange, precipitation and complexation. Reduction and surface accumulation of metals may be a process by which microorganisms protect themselves from the toxic effects of metallic ions. This study shows the biosorption of silver in the form of nanoparticles by the Bacillus koriensis. These nanoparticles that can be attributed to surface binding of stabilizing materials secreted by the Bacteria.

In this study, extracellular synthesis of AgNPs has been shown from silver-resistant Bacillus $\mathrm{k}$ sp. XRD analysis showed that nanoparticles were crystalline and metallic in nature, respectively. HRTEM analysis showed that most of the particles were spherical in shape with size $\sim 10 \mathrm{~nm}$. The extracellular bacterial synthesis of AgNPs

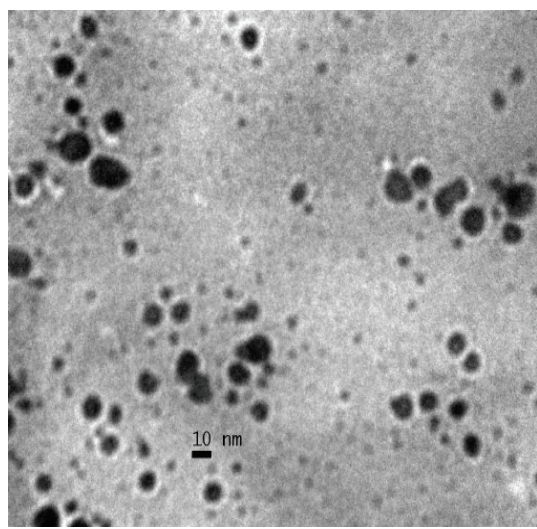

(a)

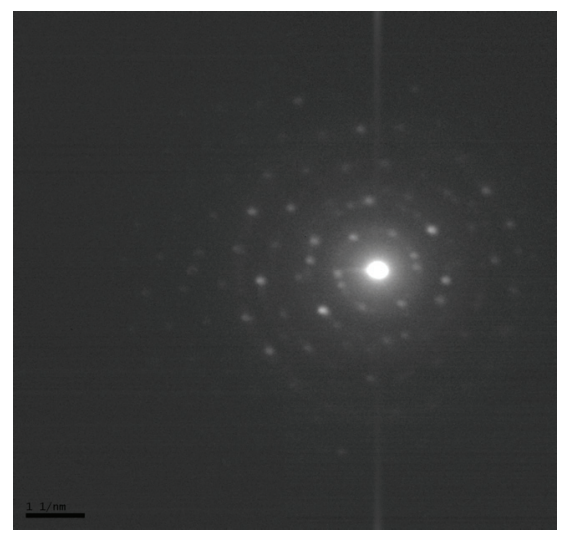

(c)

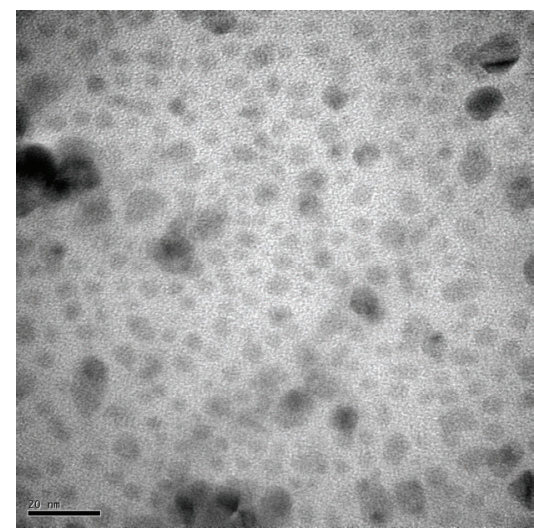

(b)

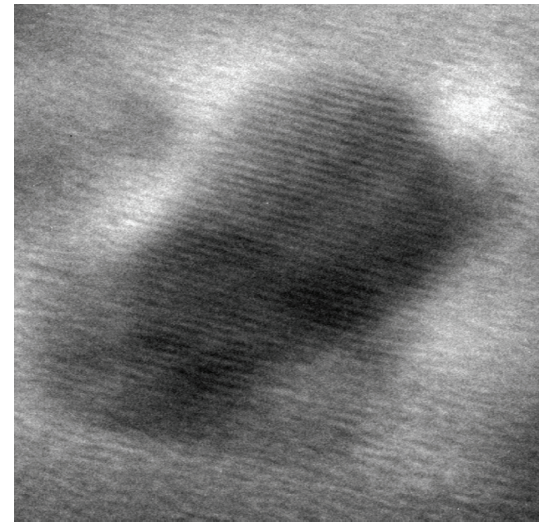

(d)

Figure 5. (a) and (b) Transmission electron microscopy images of AgNPs from Bacillus koriensis at different magnifications; (c) Selected area electron diffraction showing the characteristic crystal planes of elemental silver; (d) HRTEM image showing characteristic d spacing for the $[200]$ plane 


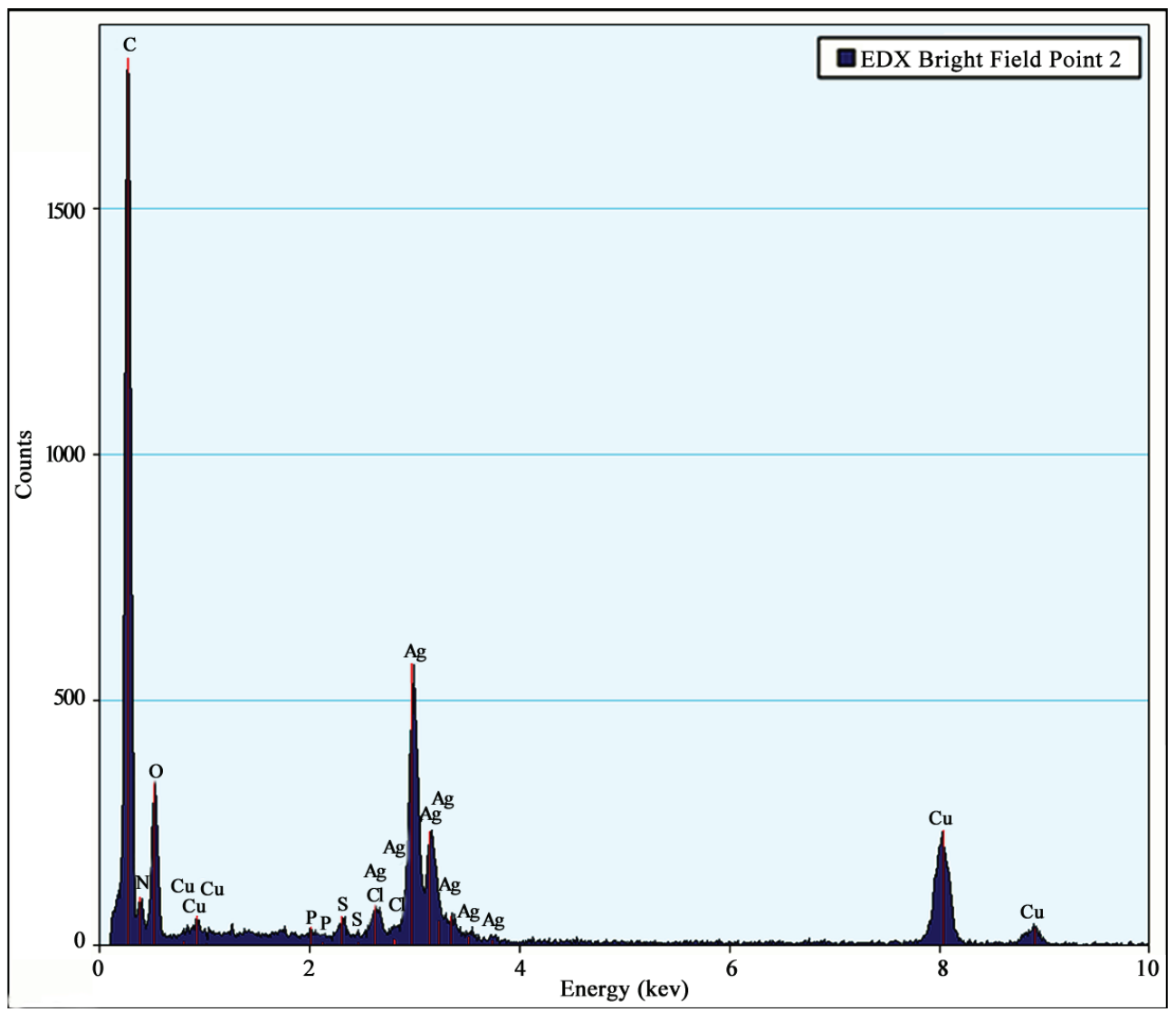

Figure 6. Energy dispersive absorption spectroscopy photograph of AgNPs

has many advantages and might be an excellent means of developing an ecologically friendly protocol. The bacterium was highly resistant to silver cations. Thus it can be safely said that metal microbe interactions have an important role in many biotechnological applications including biomineralization. So, today it seems to be a cheap and viable method for the production of ecofriendly nanoparticles.

\section{Acknowledgements}

The authors wish to acknowledge University Grants Commission, New Delhi, India for the financial support under the major research project scheme.

\section{REFERENCES}

[1] S. Edelstein and R. C. Cammarata, "Nanomaterials: Synthesis, Properties and Applications," Institute of Physics Publishings, 1996.

[2] P. Jauho and E. V. Buzaneva, "Frontiers in Nanoscale Science of Micron/Submicron Devices," Kluwer Academic Publishers, 1996.

[3] S. E. Mcneil, "Nanotechnology for the Biologist," Journal of Leukocyte Biology, Vol. 78, 2005, p. 85.
[4] A. T. Bull, M. Goodfellow and J. H. Slater, "Biodiversity as a Source of Innovation in Biotechnology," Annual Review of Microbiology, Vol. 46, 1992, p. 219.

[5] G. Southham and T. J. Beveridge, "The Occurrence of Sulfur and Phosphorus within Bacterially Derived Crystalline and Pseudocrystalline Octahedral Gold Formed in Vitro," Geochimica et Cosmochimica Acta, Vol. 60, 1996, p. 4369.

[6] T. J. Beveridge and R. G. E. Murray, "Sites of Metal Deposition in the Cell Wall of Bacillus Subtilis," Journal of Bacteriology, Vol. 141, 1980, p. 876.

[7] C. T. Dameron, R. N. Reese, R. K. Mehra, A. R. Kortan, P. J. Carroll, M. L. Steigerwald, L. E. Brus and D. R. Winge, "Biosynthesis of Cadmium Sulphide Quantum Semiconductor Crystallites," Nature, Vol. 338, 1989, p. 596.

[8] T. Klaus, R. Joerger, E. Ollson and C. G. Granquist, "Lactobacillus Assisted Synthesis of Titanium Nanoparticles," Trends Biotechnology, Vol. 19, 2001, p. 15.

[9] R. Joerger, T. Klaus and C. G. Granquist, "Biologically Produced Silvercarbon Composite Materials for Optically Functional Thin-Film Coatings," Advanced Materials, Vol. 12, 2000, p. 407.

[10] P. Mukherjee, A. Ahmad, D. S. Mandal, S. Senapati, R. Sainkar, M. I. Khan, R. Parishcha, P. V. Ajaykumar, M. 
Alam, R. Kumar and M. Sastry, "Fungus-Mediated Synthesis of Silver Nanoparticles and Their Immobilization in the Mycelial Matrix: A Novel Biological Approach to Nanoparticle Synthesis," Nano Letters, Vol. 1, 2001, p. 515.

[11] S. S. Shankar, A. Ahmad and M. Sastry, "Geranium Leaf Assisted Biosynthesis of Silver Nanoparticles," Biotechnology Progress, Vol. 19, 2003, p. 1627.

[12] B. Ankamwar, C. Damle, A. Ahmad and M. Sastry, "Biosynthesis of Gold and Silver Nanoparticles Using Emblica Officinalis Fruit Extract," Journal of Nanoscience and Nanotechnology, Vol. 5, 2005, p. 1665.

[13] K. C. Bhainsa and S. F. D'Souza, "Extracellular Biosynthesis of Silver Nanoparticles Using the Fungus Aspergillus Fumigates," Colloids and Surfaces B: Biointerfaces, Vol. 47, 2006, p. 160.

[14] M. F. Lengke, M. E. Fleet and S. Gordon, "Biosynthesis of Silver Particles Filamentous Cyanobacteria from a Silver(I) Nitrate Complex," Langmuir, Vol. 23, 2007, p. 2694.

[15] R. R. Naik, S. J. Stringer, G. Agarwal, S. E. Jones and M. O. Stone, "Biomimetic Synthesis and Patterning of Silver Nanoparticles," Nature Materials, Vol. 1, 2002, p. 169.

[16] N. Durán, P. D. Marcato, O. L. Alves, G. I. H. De Souza and E. Esposito, "Mechanistic Aspects of Biosynthesis of Silver Nanoparticles by Several Fusarium Oxysporum Strains," Journal of Nanobiotechnology, Vol. 3, 2005, p. 8.

[17] D. Fortin and T. J. Beveridge, "From Biology to Biotechnology and Medical Application," In: E. Baeuerlein, Ed., Biomineralisation, Wiley-VCH, Verlag, 2000, p. 294.

[18] A. O. Summers and S. Silver, "Microbial Transformations of Metals," Annual Review of Microbiology, Vol. 32, 1978, p. 637.

[19] D. A. Rouch, B. T. O. Lee and A. P. Morby, "Understanding Cellular Responses to Toxic Agents: A Model for Mechanism-Choice in Bacterial Metal Resistance," Journal of Industrial Microbiology, Vol. 14, 1995, p. 132.

[20] J. T. Trevors, "Silver Resistance and Accumulation in Bacteria," Enzyme and Microbial Technology, Vol. 9, 1987, p. 331.

[21] T. J. Beveridge, M. N. Hughes, H. Lee, K. T. Leung, R. K. Poole, I. Savvaidis, S. Silver and J. T. Trevor, "MetalMicrobe Interactions: Contemporary Approaches," $A d$ vances in Microbial Physiology, Vol. 38, 1977, p. 177.

[22] T. Klaus, R. Joerger, E. Ollson and C.-G. Granqvist, "Silver-Based Crystalline Nanoparticles, Microbially Fabricated," Proceedings of the National Academy of Sciences, USA, Vol. 96, 1999, p. 13611.

[23] A. Ahmad, P. Mukherjee, D. Mandal, S. Senapati, M. I. Khan, R. Kumar and M. Sastry, "Extracellular Biosynthesis of Monodisperse Gold Nanoparticles by a Novel Extremophilic Actinomycete, Thermomonospora sp.,"
Journal of the American Chemical Society, Vol. 124, 2002, p. 12108.

[24] A. Ahmad, M. I. Khan, S. Senapati, R. Kumar and M. Sastry, Langmuir, Vol. 19, 2003, p. 3550.

[25] V. Bansal, D. Rautaray, A. Bharde, K. Ahire, A. Sanyal, A. Ahmad and M. Sastry, "Fungus-Mediated Biosynthesis of Silica and Titania Particles," Journal of Materials Chemistry, Vol. 15, 2005, p. 2583.

[26] D. P. Cunningham and L. L. Lundie, "Precipitation of Cadmium by Clostridium Thermoaceticum," Applied and Environment Microbiology, Vol. 59, 1993, p. 7.

[27] D. Mandal, M. E. Bolander, D. Mukhopadya, G. Sarkar and P. Mukherjee, "The Use of Microorganisms for the Formation of Metal Nanoparticles and Their Application," Applied Microbiology and Biotechnology, Vol. 69, 2006, p. 485.

[28] U. Kreibig and M. Vollmer, In: U. Gonser, R. M. Osgood, M. B. Panish, H. Sakaki, Eds., Optical Properties of Metal Clusters, Springer, Berlin, 1995, pp. 207-234.

[29] R. M. Slawson, M. I. Van Dyke, H. Lee and J. T. Trevors, "Germanium and Silver Resistance, Accumulation, and Toxicity in Microorganisms," Plasmid, Vol. 27, 1992, p. 72.

[30] A. Gupta, K. Matsui, L. Jeng-Fan and S. Silver, "Molecular Basis for Resistance to Silver Cations in Salmonella," Nature Medicine, Vol. 5, 1999, p. 183.

[31] P. R. Selvakannan, A. Swami, D. Srisathiyanarayanan, P. S. Shirude, R. Pasricha, A. B. Mandale and M. Sastry, "Synthesis of Aqueous Au Core-Ag Shell Nanoparticles Using Tyrosine as a pH-Dependent Reducing Agent and Assembling Phase-Transferred Silver Nanoparticles at the Air-Water Interface," Langmuir, Vol. 20, 2004, p. 7825.

[32] S. S. Shankar, A. Rai, A. Ahmad and M. Sastry, "Controlling the Optical Properties of Lemongrass Extract Synthesized Gold Nanotriangles and Potential Application in Infrared-Absorbing Optical Coatings," Chemistry of Materials, Vol. 17, 2005, p. 566.

[33] The XRD patterns were indexed with reference to the crystal structures from the ASTM chart card No.04-0783.

[34] A. Gole, C. Dash, V. Ramachandran, S. R. Sainkar, A. B. Mandale, M. Rao and M. Sastry, "Pepsin-Gold Colloid Conjugates: Preparation, Characterization, and Enzymatic Activity," Langmuir, Vol. 17, 2001, p. 1674.

[35] S. Mandal, S. Phadtare and M. Sastry, "Interfacing Biology with Nanoparticles," Current Applied Physics, Vol. 5, 2005, p. 118.

[36] M. Sastry, A. Ahmad, M. IslamKhan and R. Kumar, "Biosynthesis of Metal Nanoparticles Using Fungi and Actinomycete," Current Science, Vol. 85, 2003, p. 162.

[37] N. Vigneshwaran, N. M. Ashtaputre, P. V. Varadarajan, R. P. Nachane, K. M. Paralikar and R. H. Balasubramanya, "Biological Synthesis of Silver Nanoparticles Using the Fungus Aspergillus flavus," Materials Letters, Vol. 61, 2007, p. 1413. 